\title{
Simultaneous bilateral spontaneous pneumothorax and radiation pneumonitis following thoracic radiotherapy for the treatment of high grade follicular lymphoma
}

\author{
Dalia Mudawi, George Antunes, Rajesh Mamadigi
}

\section{ABSTRACT}

Introduction: Spontaneous pneumothorax is a potentially life-threatening condition but an under-recognised and rarely described complication of thoracic radiotherapy. We report a case of bilateral spontaneous pneumothoraces and radiation pneumonitis following moderate dose of thoracic radiation to the spine for high grade follicular lymphoma. Case Report: A 66-year-old Caucasian male, non-smoker and no pre-existing pulmonary pathology, was diagnosed with low grade follicular lymphoma in 1999 and treated with chlorambucil and dexamethasone, followed by 3oGy radiotherapy to para-aortic lymph nodes. A subsequent relapse in 2005 was treated with a further eight cycles of chlorambucil and dexamethasone followed by radiotherapy to the pelvis. A second relapse in 2009 was managed with eight cycles of cyclophosphamide, vincristine and prednisolone and rituximab (CVP-R), followed by two years of maintenance rituximab. In 2016, the patient presented with thoracic back pain. Magnetic resonance imaging (MRI) demonstrated diffuse bony metastasis particularly at levels $\mathrm{T}_{2}-\mathrm{T}_{4}$ compressing the spinal cord that was decompressed surgically. Biopsy confirmed diffuse large B-cell lymphoma.

Dalia Mudawi ${ }^{1}$, George Antunes ${ }^{2}$, Rajesh Mamadigi ${ }^{3}$

Affiliations: ${ }^{1}$ Stepping Hill Hospital, Stockport, SK2 7JE, UK; 2James Cook University hospital, Marton Road, Middlesbrough, TS4 3BW, UK; ${ }^{3}$ James Cook University Hospital, Marton Road, Middlesbrough, TS4 3B, UK.

Corresponding Author: Dalia Mudawi, Stepping Hill Hospital, Stockport, SK2 7JE, UK; Email: dalia.mudawi@doctors. org.uk

Received: 19 February 2018

Accepted: 27 March 2018

Published: 24 April 2018
He received intensive chemotherapy comprising of rituximab, cyclophosphamide, doxorubicin, vincristine and prednisolone (R-CHOP) and intrathecal methotrexate. He received consolidation radiotherapy totalling $30 \mathrm{~Gy}$ over 15 fractions to the thoracic spine at levels T2$\mathrm{T} 4$ and left humerus. The patient presented to secondary care within eight weeks of completing thoracic radiotherapy complaining of worsening dyspnoea on exertion. Arterial blood gas analysis confirmed hypoxemic respiratory failure and computed tomography (CT) scan of the thorax demonstrated bilateral small to moderate sized pneumothoraces, bilateral patchy ground glass opacification suggestive of radiation pneumonitis, and atelectasis. The patient was started on a tapering course of high dose systemic corticosteroids leading to a rapid improvement in clinical symptoms and oxygenation. The pneumothoraces were monitored closely and required no intervention. Chest radiograph performed six weeks post completion of treatment showed complete resolution of the pneumothoraces and clear lung fields. Conclusion: The case highlights a rare but serious complication that presented at a relatively early stage after radiotherapy and the use of a moderate radiation dose. Vigilance of this complication is recommended and should be considered in the differential diagnosis of a patient presenting with dyspnoea after thoracic radiotherapy.

Keywords: Bilateral pneumothorax, Radiation pneumonitis, Lymphoma

\section{How to cite this article}

Mudawi D, Antunes G, Mamadigi R. Simultaneous bilateral spontaneous pneumothorax and radiation pneumonitis following thoracic radiotherapy for the treatment of high grade follicular lymphoma. J Case Rep Images Oncology 2018;4:100050Z10DM2018. 


\section{EDORIUM Journals}

J Case Rep Images Oncology 2018;4:100050Z10DM2018.

www.edoriumjournals.com/case-reports/jcro

Mudawi et al.

Article ID: 100050Z10DM2018

$* * * * * * * * *$

doi: 10.5348/100050Z10DM2018CR

\section{INTRODUCTION}

Radiotherapy is an integral treatment for many patients with cancer. The exposure of normal tissues to radiation remains an important limiting factor. The lungs are one of the most sensitive organs to ionising radiation [1]. Spontaneous pneumothorax, which is a collection on air in the pleural cavity, can be a life-threatening condition and appears to an under-recognized and rarely described complication of thoracic radiotherapy. We report a case of bilateral spontaneous pneumothoraces and radiation pneumonitis following moderate dose thoracic spine radiation for high grade follicular lymphoma.

\section{CASE REPORT}

A 66-year-old Caucasian male, non-smoker without pre-existing pulmonary pathology, was diagnosed with stage IIIa grade 2 follicular lymphoma in the year 1999. $\mathrm{He}$ was treated with ten cycles of chlorambucil and dexamethasone followed by $30 \mathrm{~Gy}$ radiotherapy to the abdominal para-aorticlymph nodes. In 2005, he presented with clinical and radiological disease progression and received a further eight cycles of chlorambucil and dexamethasone, followed by radiotherapy to right pelvis.

The patient relapsed in 2009 with Stage IVa disease with progression seen in the abdomen and pelvis predominantly. The relapse was treated with 8 cycles of CVP-R, followed by two years of maintenance rituximab.

In 2016, the patient presented with thoracic back pain. MRI demonstrated diffuse bony metastasis at levels T2-T4 with spinal cord compression. Biopsy confirmed diffuse large B-cell lymphoma consistent with transformation of low-grade disease. The patient underwent T2-T6 percutaneous pedicle screw fixation and a limited decompression at $\mathrm{T}_{3}-\mathrm{T}_{4}$ at the site of spinal cord compression. He received $30 \mathrm{~Gy}$ radiotherapy to the thoracic spine at levels $\mathrm{T}_{2}-\mathrm{T}_{4}$ as well as the left humerus over 15 fractions. Intensive chemotherapy comprising six cycles of RCHOP and intrathecal methotrexate was offered.

The patient presented to secondary care within eight weeks of completing thoracic radiotherapy complaining of worsening dyspnoea on exertion. On admission blood results showed WCC $6 \times 10^{9} / \mathrm{L}$, CRP $88 \mathrm{mg} / \mathrm{L}$ and $\mathrm{Hb} 120$ $\mathrm{g} / \mathrm{L}$. Arterial blood gas analysis confirmed hypoxemic respiratory failure with $\mathrm{pH} 7.47, \mathrm{PCO} 24.38, \mathrm{PO} 28.5$ and $\mathrm{HCO}_{3}$ 26.2. CT scan of the thorax demonstrated bilateral small to moderate sized pneumothoraces, bilateral patchy ground glass opacification suggestive of radiation pneumonitis, septal thickening and atelectasis (Figure 1.) The patient was initiated on a tapering course of systemic corticosteroid therapy starting at $60 \mathrm{mg}$ of prednisolone. This led to a rapid improvement clinically, in oxygenation and in chest radiograph appearances Figure 2(A and B). The pneumothoraces were observed closely over time and required no intervention. A chest radiograph performed six weeks post completion of treatment revealed complete re-expansion of both lungs and no evidence of fibrosis.

\section{DISCUSSION}

Radiation induced lung disease (RILD) typically manifests 4-12 weeks (early phase) after completion of radiotherapy as a transient pneumonitis with radiological evidence of ground-glass opacification or consolidation[2]. In the late phase, 6-12 months after

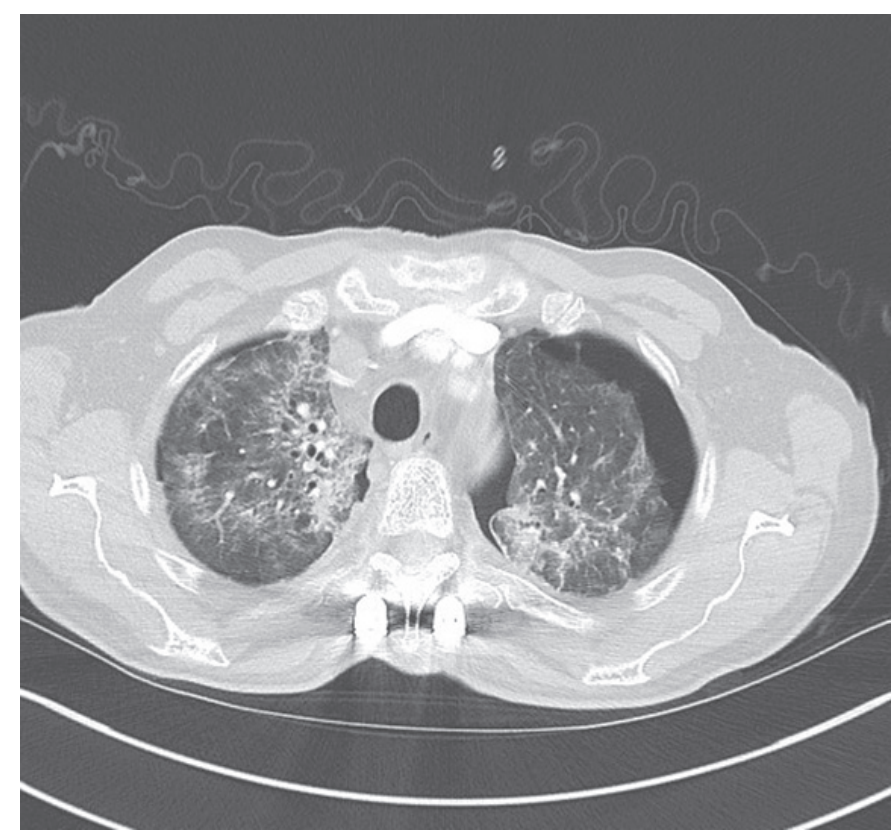

Figure 1: Computed Tomography scan demonstrating radiation pneumonitis and bilateral pnuemothoraces.

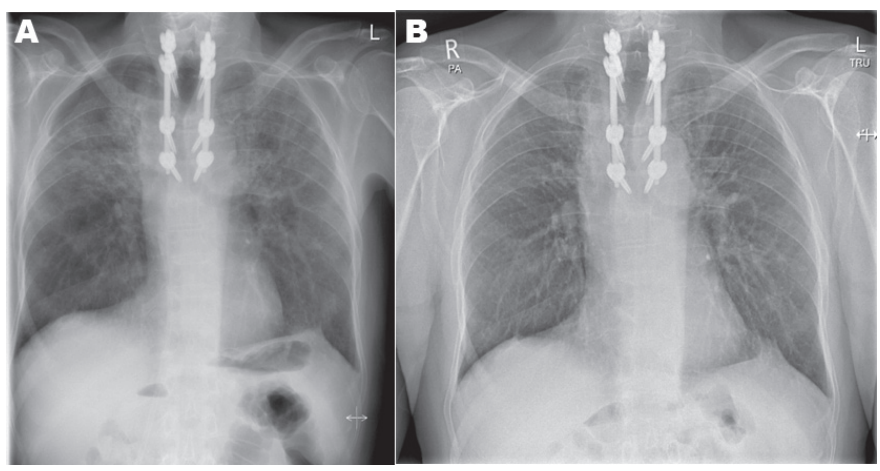

Figure 2(A and B): Pre-treatment (A) and post-treatment (B) chest radiograph imaging demonstrating resolving pneumonitis eight weeks post steroid initiation. 


\section{EDORIUM Journals}

radiotherapy, RILD presents as traction bronchiectasis, linear scarring, volume loss or radiation fibrosis [2, 3]. The early (<90 days) and Late (>90 days) radiotherapyinduced effects to the lung are graded by the Radiation Therapy Oncology Group (Table 1). The National Cancer Institute (NCI) later revised the severity of adverse reactions (CTCv3.0) (Table 2) [4].

Various factors influence the degree or severity of RILD. These include patient age, prior or concomitant chemotherapy, and irradiation technique [3]. The volume of lung irradiated, the total dose of radiation delivered and the fractionation of the dose are also vital factors. RILD rarely occurs in patients receiving less than 20Gy and almost always presents in patients who receive greater than 40Gy [3]. Chemotherapy agents such as actinomycin D, adrinomycin, bleomycin, cyclophosphamide and busulphan can potentiate the effects of radiotherapy [5, $6]$.

The functional subunit of the lung is the alveolarcapillary complex. Endothelial, epithelial and reticuloendothelial system cells are particularly sensitive to radiation. Radiation damages these cells by apoptosis and release of stress response genes [1]. Reactive oxygen and nitrogen species cause oxidative injury to cellular structures resulting in cell necrosis. The DNA damage caused by radiation leads to apoptosis of type 1 and type 2 pneumocytes and disrupts the epithelial and endothelial barrier. As a result of this, inflammatory cells move to the damaged region [7].
Transforming growth factor beta 1 (TGF- $\beta 1$ ) is a multifunctional peptide that plays a vital role in the development radiation fibrosis. Release of TGF- $\beta 1$ in tissue exposed to radiation leads to stimulation of fibroblasts and changes in the lung structure by transforming relevant cells to myofibroblasts [8]. An inflammatory response follows with macrophage accumulation and activation. Increased oxygen consumption and vascular changes contribute to hypoxia. Hypoxia stimulates production of pro-inflammatory, profibrogenic, and proangiogenic cytokines [2].

Spontaneous pneumothorax is unusual and the majority of cases in the medical literature have been reported in patients receiving mantle irradiation for lymphoma [9]. Pezner et al. reported the incidence of pneumothorax after mantle irradiation at $2.2 \%$ in Hodgkin's disease patients without concurrent lung disease [10]. Rowinsky et al described 11 patients with spontaneous pneumothorax following radiation therapy of which ten had thoracic irradiation for lymphoma and a single patient had breast cancer [11]. A retrospective review by Chan et al examined at 546 patients with solid organ cancers and found that 25 out of 546 had developed spontaneous pneumothorax, of which eight had received prior radiotherapy [12].

The mean time to presentation of a pneumothorax following radiation therapy is reported as 16 months by Pezner et al. [10]. A very small number of bilateral and recurrent pneumothoraces have been reported [13].

Table 1: The Radiation Therapy Oncology Group: Early and Late radiotherapy-induced effects to the lung.

\begin{tabular}{|c|c|c|c|c|c|}
\hline & Grade 1 & Grade 2 & Grade 3 & Grade 4 & Grade 5 \\
\hline $\begin{array}{l}\text { Early } \\
<90 \text { days }\end{array}$ & $\begin{array}{l}\text { Mild symptoms } \\
\text { Dry cough or exercise } \\
\text { dyspnoea }\end{array}$ & $\begin{array}{l}\text { Persistent cough } \\
\text { requiring narcotic, } \\
\text { antitussive agents } \\
\text { Dyspnoea with minimal } \\
\text { exercise }\end{array}$ & $\begin{array}{l}\text { Cough not responding } \\
\text { to narcotic, antitussive } \\
\text { agents } \\
\text { Clinical or radiological } \\
\text { symptoms of acute } \\
\text { pneumonia } \\
\text { Intermittent oxygen } \\
\text { needed }\end{array}$ & \multicolumn{2}{|c|}{$\begin{array}{l}\text { Respiratory insufficiency requiring } \\
\text { oxygen or mechanical ventilation } \\
\text { continuously }\end{array}$} \\
\hline $\begin{array}{l}\text { Late }>90 \\
\text { days }\end{array}$ & $\begin{array}{l}\text { Asymptomatic or } \\
\text { mild symptoms (dry } \\
\text { cough) } \\
\text { Slight radiographic } \\
\text { appearances }\end{array}$ & $\begin{array}{l}\text { Moderate symptomatic } \\
\text { fibrosis or pneumonitis } \\
\text { (severe cough) } \\
\text { Low grade fever } \\
\text { Patchy radiographic } \\
\text { appearances }\end{array}$ & $\begin{array}{l}\text { Severe symptomatic } \\
\text { fibrosis or pneumonitis } \\
\text { Dense radiographic } \\
\text { changes }\end{array}$ & $\begin{array}{l}\text { Severe respiratory } \\
\text { insufficiency } \\
\text { Continuous } \mathrm{O} 2 \\
\text { Assisted ventilation }\end{array}$ & Death \\
\hline
\end{tabular}

Table 2: CTC V3 criteria in the evaluation of side effects in radiation pneumonia [4]

\begin{tabular}{|c|c|c|c|c|c|}
\hline Side effect & Grade 1 & Grade 2 & Grade 3 & Grade 4 & Grade 5 \\
\hline $\begin{array}{l}\text { Pneumonitis/ } \\
\text { pulmonary } \\
\text { infiltrates }\end{array}$ & $\begin{array}{l}\text { Pneumonitis } \\
\text { Asymptomatic, } \\
\text { radiographic } \\
\text { findings only }\end{array}$ & $\begin{array}{l}\text { Symptomatic, not } \\
\text { interfering with ADL }\end{array}$ & $\begin{array}{l}\text { Symptomatic, } \\
\text { interfering with } \\
\text { ADL; O2 indicated }\end{array}$ & $\begin{array}{l}\text { Life-threatening; } \\
\text { ventilatory support } \\
\text { indicated }\end{array}$ & Mortality \\
\hline
\end{tabular}




\section{EDORIUM Journals}

Another review by Asai et al., reported the outcome of pneumothorax after stereotatic body radiotherapy for lung tumors. They reported 12 cases of pneumothorax post radiation pneumonitis or fibrosis [14]. In most cases a pneumothorax was incidentally diagnosed on follow-up CT, the pneumothorax was self-limiting and required no pleural intervention [14].

The pathogenesis behind the post radiation pneumothorax is yet to be clearly defined. Radiation induced pulmonary changes involving predominantly the apical pleura and parenchymal injury may be responsible [15]. Focal emphysema and fibrosis due to radiation therapy increases the chance of the formation and rupture of subpleural blebs [9]. Furthermore, increased tissue traction due to fibrosis can lead to the development of pneumothorax [16]. The radiation dose to the lung appears to be higher in the apex due to a smaller thoracic diameter. This results in higher radiation doses in this region [5]. In certain cases, the mechanism may involve post radiation shrinkage of the centrally obstructing tumor leading to a check-valve effect. This later results in air trapping, alveolar hyperinflation and pneumothorax [9].

The response to corticosteroid in radiation pneumonia is generally favourable. The decision for systemic corticosteroid therapy is made on clinical symptoms and investigations compatible with a grade 2 or higher radiation pneumonia (CTC criteria) (Table 2). An initial dose of $0.5^{-1} \mathrm{mg} / \mathrm{kg}$ of prednisone is recommended followed by a tapering course.

The management of a pneumothorax should be according to British thoracic guidelines (BTS) [17]. The BTS guidelines advise pleural intervention if the rim of air is $>2 \mathrm{~cm}$ between the lung edge and chest wall or the patient is symptomatic. Patients who are asymptomatic with a small pneumothorax may be managed conservatively. Surgical intervention or talc administration via an intercostal tube may be required in complicated cases, i.e., presence of a persistent air leak.

\section{CONCLUSION}

This case highlights a rare but serious complication that presented at a relatively early stage after moderate radiation dose to the thoracic spine. Although, the pathophysiology of post radiation pneumothorax is yet to be clearly defined, a literature review has identified a strong association with radiation-related lung fibrosis. Modern radiotherapy techniques (using lower doses of radiation) and the development of pneumothorax should be evaluated in ongoing and future clinical trials. Awareness of this complication is recommended and should be considered in the differential diagnosis of a patient presenting with dyspnoea after thoracic radiotherapy.

\section{REFERENCES}

1. Arguder E, A Yildirim B, Hasanoglu HC. Pulmonary toxicities and treatment of radiation therapy. Eurasian J Pulmonol 2015;16(3):150-8.

2. Diederich S. Chest CT for suspected pulmonary complications of oncologic therapies: How I review and report. Cancer Imaging 2016 Apr 11;16:7.

3. Choi YW, Munden RF, Erasmus JJ, et al. Effects of radiation therapy on the lung: Radiologic appearances and differential diagnosis. Radiographics 2004 JulAug;24(4):985-97.

4. Trotti A, Colevas AD, Setser A, et al. CTCAE v3.0: Development of a comprehensive grading system for the adverse effects of cancer treatment. Semin Radiat Oncol $2003 \mathrm{Jul} ; 13(3): 176-81$.

5. Penniment MG, O’Brien PC. Pneumothorax following thoracic radiation therapy for Hodgkin's disease. Thorax 1994 Sep;49(9):936-7.

6. Sostman HD, Putman CE, Gamsu G. Review: Diagnosis of chemotherapy lung. AJR Am J Roentgenol 1981 Jan;136(1):33-40.

7. Trott KR, Herrmann T, Kasper M. Target cells in radiation pneumopathy. Int $\mathrm{J}$ Radiat Oncol Biol Phys 2004 Feb 1;58(2):463-9.

8. Abratt RP, Morgan GW, Silvestri G, Willcox P. Pulmonary complications of radiation therapy. Clin Chest Med 2004 Mar;25(1):167-77.

9. Bhardwaj H, Bhardwaj B, Youness HA. A case of spontaneous pneumothorax following radiation therapy for non-small cell lung cancer. Lung India 2013 Oct;30(4):360-2.

10. Pezner RD, Horak DA, Sayegh HO, Lipsett JA. Spontaneous pneumothorax in patients irradiated for Hodgkin's disease and other malignant lymphomas. Int J Radiat Oncol Biol Phys 1990 Jan;18(1):193-8.

11. Rowinsky EK, Abeloff MD, Wharam MD. Spontaneous pneumothorax following thoracic irradiation. Chest 1985 Nov;88(5):703-8.

12. Chan SN, Okuno SH, Jatoi A. Causes and outcomes of spontaneous pneumothoraces in solid tumor cancer patients: An update for the medical oncologist. J Thorac Oncol 2006 May;1(4):335-8.

13. Mesurolle B, Qanadli SD, Merad M, et al. Unusual radiologic findings in the thorax after radiation therapy. Radiographics 2000 Jan-Feb;20(1):67-81.

14. Asai K, Nakamura K, Shioyama Y, et al. Clinical characteristics and outcome of pneumothorax after stereotactic body radiotherapy for lung tumors. Int $\mathrm{J}$ Clin Oncol 2015 Dec;20(6):1117-21.

15. Ohnishi K, Shioyama Y, Nomoto S, et al. Spontaneous pneumothorax after stereotactic radiotherapy for non-small-cell lung cancer. Jpn J Radiol 2009 Aug;27(7):269-74.

16. Okada M, Ebe K, Matsumoto $\mathrm{T}$, et al. Ipsilateral spontaneous pneumothorax after rapid development of large thin-walled cavities in two patients who had undergone radiation therapy for lung cancer. AJR Am J Roentgenol 1998 Apr;170(4):932-4.

17. Havelock T, Teoh R, Laws D, Gleeson F; BTS pleural disease guideline group. Pleural procedures and thoracic ultrasound: British thoracic society pleural disease guideline 2010. Thorax 2010 Aug;65 Suppl 2:ii61-76. 


\section{EDORIUM Journals}

J Case Rep Images Oncology 2018;4:100050Z10DM2018.

www.edoriumjournals.com/case-reports/jcro

Mudawi et al. 5

\section{$* * * * * * * * *$}

\section{Author Contributions}

Dalia Mudawi - Substantial contributions to conception and design, Acquisition of data, Drafting the article, Revising it critically for important intellectual content, Final approval of the version to be published

George Antunes - Substantial contributions to conception and design, Acquisition of data, Drafting the article, Revising it critically for important intellectual content, Final approval of the version to be published

Rajesh Mamadigi - Acquisition of data, Revising it critically for important intellectual content, Final approval of the version to be published

\section{Guarantor of Submission}

The corresponding author is the guarantor of submission.

\section{Source of Support \\ None}

\section{Consent Statement}

Written informed consent was obtained from the patient for publication of this case report.

\section{Conflict of Interest}

Authors declare no conflict of interest.

\section{Copyright}

(C) 2018 Dalia Mudawi et al. This article is distributed under the terms of Creative Commons Attribution License which permits unrestricted use, distribution and reproduction in any medium provided the original author(s) and original publisher are properly credited. Please see the copyright policy on the journal website for more information.
Access full text article on other devices

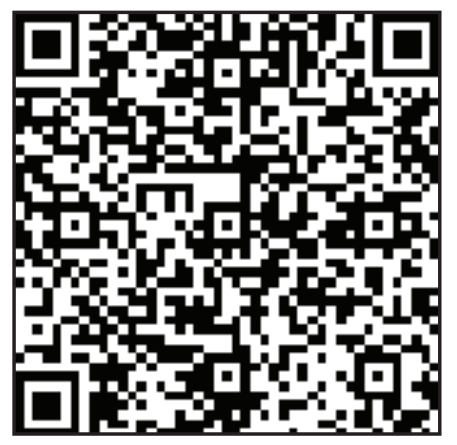

Access PDF of article on other devices

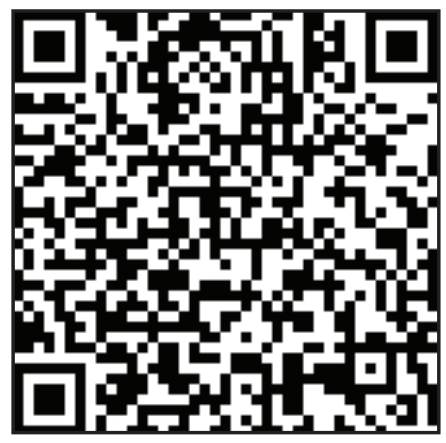

